\title{
Effects of Nanosecond Pulsed Electric Field Exposure on Arabidopsis thaliana
}

\author{
Christian J. Eing ${ }^{1}$, Simone Bonnet ${ }^{2}$, Michael Pacher ${ }^{2}$, Holger Puchta ${ }^{2}$ and Wolfgang Frey ${ }^{1}$ \\ Karlsruhe Institute of Technology (KIT) \\ ${ }^{1}$ Forschungszentrum Karlsruhe GmbH \\ ${ }^{2}$ University of Karlsruhe \\ Inst. f. Pulsed Power and Microwave Technology \\ Hermann-v-Helmholtz-Platz 1 \\ DE-76344 Eggenstein-Leopoldshafen \\ Botanical Institute II \\ Fritz-Haber-Weg 4 \\ DE-76128 Karlsruhe
}

\begin{abstract}
Seven days old seedlings of Arabidopsis thaliana, suspended in a $0.4 \mathrm{~S} / \mathrm{m}$ buffer solution were exposed to nanosecond pulsed electric fields (nSPEF) with a duration of $10 \mathrm{ns,}$ $25 \mathrm{~ns}$ and $100 \mathrm{~ns}$. The electric field was varied from $5 \mathrm{kV} / \mathrm{cm}$ up to $50 \mathrm{kV} / \mathrm{cm}$. The specific treatment energy ranged between $100 \mathrm{~J} / \mathrm{kg}$ and $10 \mathrm{~kJ} / \mathrm{kg}$. Due to electroporation of the plasmamembrane of the plant cells, the seedlings completely died off, when $100 \mathrm{~ns}$ pulses and high electric field pulses were applied. But even at the highest specific treatment energies, $10 \mathrm{~ns}$ pulses had no lethal effect on the seedlings. An evaluation of the leaf area 5 and 7 days after pulsed electric field treatment revealed values twice the area of sham treated seedlings up to a specific treatment energy of $4 \mathrm{~kJ} / \mathrm{kg}$, when the applied field amplitude was low or the pulse duration $10 \mathrm{~ns}$. A growth stimulating effect after short pulse exposition clearly could be detected. Contrary to the growth inhibiting effect of plasmamembrane electroporation on the seedlings, a growth stimulation by nSPEF treatment does not scale with the treatment energy within the applied parameter range.
\end{abstract}

Index Terms - Pulsed electric field (PEF) treatment, electroporation, growth stimulation, intracellular effects.

\section{INTRODUCTION}

THE interaction of pulsed electric fields with biological cells suspended in a conductive liquid commonly is accepted to lead to the formation of aqueous pores in the plasmamembrane. In this case the electric field pulses are long compared to the time needed for the charging of the plasmamembrane to a value in the range of $0.5-1 \mathrm{~V}$, where an increased membrane permeability can be observed. In the early 70 's Neumann et al proposed that the externally induced electric field across the membrane forces the phospholipid molecules to rearrange and to form hydrophilic pores [1], which allow an exchange of ions and molecules through the membrane. At the same time Zimmermann [2] addressed this permeability increase to a dielectric breakdown and a partial rupture of the membrane, respectively.

Nowadays, this effect is commonly known as electroporation [3] and is applied for gene and drug delivery to cells $[4,5]$, for bacterial decontamination $[6,7]$, food processing [8] and for cell ingredients extraction $[9,10]$.
When applying moderate external electric field amplitudes of several $\mathrm{kV} / \mathrm{cm}$ and pulse rise times in the microsecond range the electric field along the cell is displaced into the membrane and the electric field across the cell interior is negligible. Whereas for steep and high amplitude electric field pulses, i.e. for pulse rise times which are considerably shorter than the charging time of the membrane, the electric field penetrates into the cell interior $[11,12]$. The displacement current can charge intracellular membranes and affect cell organelles. There is a broad variety of responses of mammalian cells to ns pulsed electric field exposition [13] such as the intracellular calcium release $[14,15]$, phosphatidylserine externalization [16] and DNA damage [17]. A promising application of nsPEFs is the killing of melanoma cells [18].

Contrary, there is only little information available from literature about the effect of nanosecond pulsed electric field exposure on plant cells and tissue. Akiyama et al reported about a growth stimulating effect on mushrooms, when applying $140 \mathrm{kV}, 200 \mathrm{~ns}$ pulses to a $1.2 \mathrm{~m}$ long wood log inoculated with shiitake mushroom [19]. The yield of

Manuscript received on 22 April 2009, in final form 16 July 2009. 
mushrooms after pulsed electric field treatment was almost doubled. Takaki et al came to comparable results when treating a $0.9 \mathrm{~m}$ long wood $\log$ inoculated with nameko fungus with $120 \mathrm{kV}, 100 \mathrm{~ns}$ pulses. They found, that mushroom growth was increased by a factor of 1.5 [20].

A growth stimulating effect on plant seedlings and seed could also be observed for static and slowly varying $(50 / 60 \mathrm{~Hz})$ electric fields. In these studies the applied field strength varied from some $10 \mathrm{~V} / \mathrm{cm}$ to $12 \mathrm{kV} / \mathrm{cm}$. At comparable low field strengths of $36 \mathrm{~V} / \mathrm{cm}, 50 \mathrm{~Hz}$, applied to soy seedlings the average seedling length was increased by $12 \%$ [21], while a dc field of the same magnitude did not affect seedling growth. In contrast, no prolonged effect on the germination rate of soy beans could be observed after a RFfield treatment at $100 \mathrm{MHz}$ [22]. Moon and Chung observed an accelerated germination when exposing tomato seeds to a $4-12 \mathrm{kV} / \mathrm{cm}$ ac electric field for one minute [23]. For potatoe seed a positive influence on seed yield was reported, when treating them for $12 \mathrm{~min}$ with a $4 \mathrm{kV} / \mathrm{cm}$ electrostatic field prior to sowing [24]. Bachman [25] found a growth stimulation on barley, for a five day long electrostatic field exposure of $0.5 \mathrm{kV} / \mathrm{cm}$. No growth stimulation was obtained at a field strength of $2 \mathrm{kV} / \mathrm{cm}$. Summarizing, the majority of the studies report about an increase in germination rate and plant growth on the order of $10-20 \%$.

The objective of this work was to identify phenotypic changes of the plant growth after a nanosecond pulsed electric field treatment within a wide parameter range of the applied field strength and the expended specific treatment energy.

\section{MATERIALS AND METHODS}

Arabidopsis seeds (ecotype Columbia-0, [26]) were surface sterilized in order to remove putative contaminants. The seeds were filled into an $1.5 \mathrm{ml}$ reaction tube and incubated at room temperature for 15 minutes in $4 \%$ sodium hypochlorite solution with a small amount of Tween-20 on a bench shaker. Subsequently, the seeds were pelleted by centrifugation ( 20 seconds, $600 \mathrm{~g}$ ) and the supernatant was removed under axenic conditions. Seeds were then washed five times with sterile water (20 second centrifugation steps, $600 \mathrm{~g}$ ) and then stored in $1 \mathrm{ml}$ sterile agarose solution $(1 \% \mathrm{w} / \mathrm{v})$ for two days at $4{ }^{\circ} \mathrm{C}$ for stratification. The seeds were then sown with a pipette on $90 \mathrm{~mm}$ petri dishes containing solid medium (GM, $4.9 \mathrm{~g} / \mathrm{l}$ Murashige \& Skoog micro and macro elements [27] including vitamins purchased from Duchefa, Haarlem, The Netherlands, catalog no. M 0222.0050, $10 \mathrm{~g} / \mathrm{l}$ sucrose, $\mathrm{pH}$ 5.7) with $8 \mathrm{~g} / \mathrm{l}$ micro agar (Duchefa, Haarlem, The Netherlands, catalog no. M 1002) and were cultivated in a growth chamber for seven days (PERCIVAL CU-36L [CLF Laborgeräte $\mathrm{GmbH}$, Emersacker]) under tightly controlled conditions ( $16 \mathrm{~h}$ light, $24{ }^{\circ} \mathrm{C} / 8 \mathrm{~h}$ dark, $20^{\circ} \mathrm{C} / 100 \mu \mathrm{M}$ PHAR, Photosynthetic Active Radiation).

Immediately before pulsed electric field treatment, 10 seedlings were carefully removed from the agar plate, resuspended in $4 \mathrm{mS} / \mathrm{cm}$ treatment buffer $(40 \mathrm{mM} \mathrm{KCl}, \mathrm{pH}$ adjusted to 6.5 with TRIS/MES) and filled into a electroporation cuvette. Each cuvette was filled directly before pulse treatment and overlayed with purified and sterile paraffin oil. This prevents surface flashover at high field strength values. After pulsed electric field treatment, the paraffin oil was removed with a pipette and seedlings were washed out of the cuvette and carefully redistributed on a fresh agar plate and cultivated for up to eleven days in the PERCIVAL growth chamber. At every parameter setting, 3 treatments with 10 seedlings each were made. Five sham treatment cycles were performed identical to the pulsed electric field treatment procedure but without applying electric field pulses to the seedlings.

Electroporation cuvettes (BTX Instrument Division, Holliston, MA, USA) with a rated electrode distance of $4 \mathrm{~mm}$ and a volume of $800 \mu 1$ were used as treatment chambers during all experiments. The variation of the electrode distance was measured to be $\pm 0.1 \mathrm{~mm}$ in maximum.

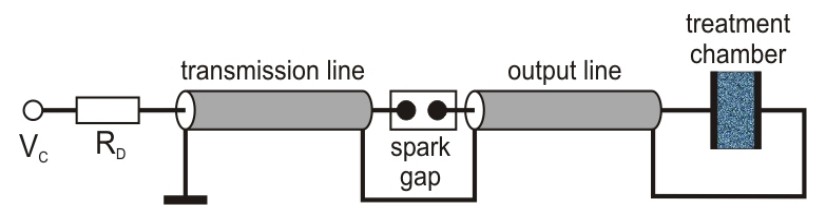

Figure 1. Schematic of the transmission line generator used for the experiments.

Rectangular pulses with a pulse amplitude of $2 \mathrm{kV}, 4 \mathrm{kV}$, $8 \mathrm{kV}$ and $20 \mathrm{kV}$ corresponding to a field strength of $5 \mathrm{kV} / \mathrm{cm}$, $10 \mathrm{kV} / \mathrm{cm}, 20 \mathrm{kV} / \mathrm{cm}$ and $50 \mathrm{kV} / \mathrm{cm}$ were generated by a transmission line pulse generator, Figure 1. Conventional 50 $\mathrm{Ohm}$ coaxial cables (RG 213, Belden, VillingenSchwenningen, Germany) were charged up to $40 \mathrm{kV}$ via a decoupling resistor, $R_{D}=100 \mathrm{M} \Omega$, and switched onto the output line and the treatment chamber by a corona-preionized $\mathrm{SF}_{6}$-insulated pressurized spark gap [41]. The pulse duration was adjusted by varying the length of the transmission line cable. For our experiments, the cable length was varied between $1 \mathrm{~m}, 2.5 \mathrm{~m}$ and $10 \mathrm{~m}$ which corresponds to a pulse duration of $10 \mathrm{~ns}, 25 \mathrm{~ns}$ and $100 \mathrm{~ns}$. The output line of the generator was $1.2 \mathrm{~m}$ long.

The transmissison line pulse generator was charged by a $65 \mathrm{kV} / 8 \mathrm{~mA}$ power supply (HSC 251-065, Guth GmbH, Salach, Germany). Impulse voltage waveforms were acquired by a $500 \mathrm{MHz}$ Oscilloscope (TDS 640A, Tektronix, Beaverton, OR, USA). The voltage was measured by a calibrated Tektronix probe (P6015, Tektronix Beaverton, OR, USA). To increase the usable bandwidth of the probe, the plastic case of the probe was removed, the probe core massively connected to the system ground and a damping resistor of $50 \Omega$ was inserted between the measurement point at the set up and the high voltage tip of the probe. For probe calibration a square pulse generator with a rise time of $\mathrm{T}_{\mathrm{r}}=0.7 \mathrm{~ns}$ was used (IPG 2501, HILO-Test, Karlsruhe, Germany). The rise time of the acquisition system, i.e. probe connected to the TDS $640 \mathrm{~A}$, was better than $t_{R}=2 \mathrm{~ns}$.

In order to minimize switch impedance, which predominantly affects the pulse rise time, the spark gap was operated at a pressure range between $0.8 \mathrm{MPa}$ to $1.0 \mathrm{MPa}$. A 
coarse adjustment of the spark gap's breakdown voltage was accomplished by varying the gap distance between $0.1 \mathrm{~mm}$ and $1.0 \mathrm{~mm}$. The $10 \%$ to $90 \%$ pulse rise time of the transmission line generator was $\mathrm{T}_{\mathrm{r}}=2.5 \mathrm{~ns}$.

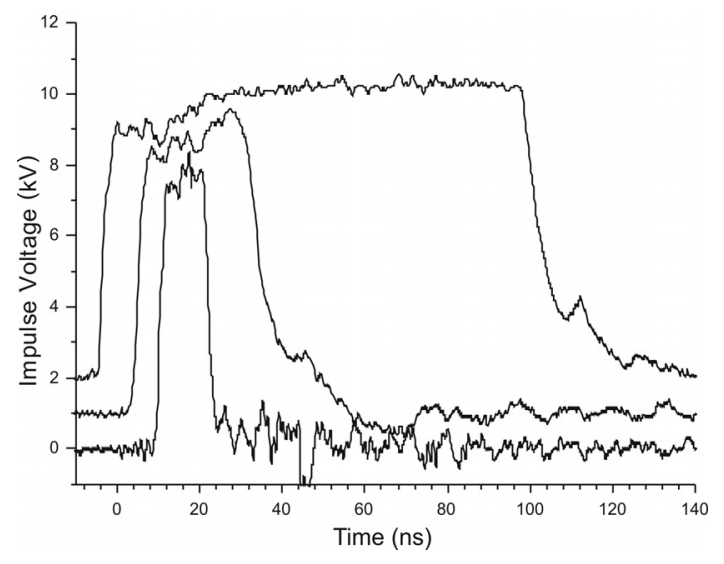

Figure 2. Output voltage waveforms of the transmission line generator for a pulse duration of $10 \mathrm{~ns}, 25 \mathrm{~ns}$ and $100 \mathrm{~ns}$ and a pulse voltage amplitude of $8 \mathrm{kV}$ delivering a $20 \mathrm{kV} / \mathrm{cm}$ field pulse across the electrodes of a $4 \mathrm{~mm}$ electroporation cuvette. For display reasons, the $25 \mathrm{~ns}$ pulse and the $100 \mathrm{~ns}$ pulse are shifted by $1 \mathrm{kV}$ and $2 \mathrm{kV}$, respectively.

The spark gap was operated in the self breakdown mode. Due to the preionization of the gap volume by an auxiliary corona discharge, accomplished by a needle-type electrode mounted at a distance of $10 \mathrm{~mm}$ to the positive polarity electrode (anode) and directly connected to the anode [41], the absolute pulse to pulse deviation of the impulse voltage amplitude from the RMS-value was better than $3 \%$. During the experiment, the time between two pulses was 5 seconds.

The pulse duration and the number of pulses were chosen for a constant specific energy delivery to the seedlings immersed into the $0.4 \mathrm{~S} / \mathrm{m}$ buffer. At each field strength 100 pulses of $10 \mathrm{~ns}$ duration, 40 pulses of $25 \mathrm{~ns}$ duration and 10 pulses of $100 \mathrm{~ns}$ duration were used as a basic parameter set, Table 1. In order to refine the energy resolution, this parameter set was supplemented by intermediate values as indicated in Table 2.

Table 1. Basic parameter set for nsPEF treatment of A. thaliana seedlings.

\begin{tabular}{|c|c|c|c|c|c|c|c|c|c|c|c|c|}
\hline $\mathrm{W}[\mathrm{J} / \mathrm{kg}]$ & \multicolumn{3}{|c|}{100} & \multicolumn{3}{|c|}{400} & \multicolumn{3}{|c|}{1600} & \multicolumn{3}{|c|}{10000} \\
\hline $\mathrm{E}[\mathrm{kV} / \mathrm{cm}]$ & \multicolumn{3}{|c|}{5} & \multicolumn{3}{|c|}{10} & \multicolumn{3}{|c|}{20} & \multicolumn{3}{|c|}{50} \\
\hline $\mathrm{T}[\mathrm{ns}]$ & 10 & 25 & 100 & 10 & 25 & 100 & 10 & 25 & 100 & 10 & 25 & 100 \\
\hline $\mathrm{N}$ & 100 & 40 & 10 & 100 & 40 & 10 & 100 & 40 & 10 & 100 & 40 & 10 \\
\hline
\end{tabular}

Table 2. Additional parameters for energy scale refinement.

\begin{tabular}{|c|c|c|c|c|c|}
\hline $\mathrm{W}[\mathrm{J} / \mathrm{kg}]$ & \multicolumn{2}{|c|}{160} & 640 & 1000 & 4000 \\
\hline $\mathrm{E}[\mathrm{kV} / \mathrm{cm}]$ & 10 & 20 & 20 & 50 & 50 \\
\hline $\mathrm{T}[\mathrm{ns}]$ & \multicolumn{5}{|l}{10} \\
\hline $\mathrm{N}$ & 40 & 10 & 40 & 10 & 40 \\
\hline
\end{tabular}

The specific energy delivered to the treatment chamber is given by the applied energy per treated mass and was calculated by $\mathrm{W}=\mathrm{N} \cdot 0.5 \cdot \mathrm{C} \cdot \mathrm{V}_{\mathrm{C}}{ }^{2} / 0.8 \times 10^{-3} \mathrm{~kg}$, whereas $\mathrm{N}$ denotes the number of pulses, $\mathrm{C}$ the capacity of the transmission line cable, i.e. $107 \mathrm{pF}$ per meter of length, and $\mathrm{V}_{\mathrm{C}}$ is the charging voltage of the transmission line. Buffer temperature and conductivity were adjusted to provide matched load conditions to the transmission line generator. During the experiments no reflections from the treatment chamber could be monitored.

Images of the seedlings were aquired with a $2560 \times 1920$ pixel resolution camera (Model E5700, Nikon). Leaf area determination was made by ImageJ [28] using the "Analyse particles" algorithm. The given values for the leaf area are averages of the total leaf area of three agar plates, containing 10 seedlings, each.

\section{RESULTS AND DISCUSSION}

Figure 3 shows images of seedlings of Arabidopsis thaliana on MS-agar-plates from the sham control. The plants on both plates passed the same experimental procedure like the nsPEF-treated seedlings except the application of electric field pulses. Compared to the nsPEF treated samples, Fig. 4, the growth of individual seedlings within a batch of ten plants is fairly uniform, Figure 3. Although the handling of the plants during the nsPEF treatment procedure assuredly stressed the plants by interrupting their continuous natural growth and by harming them due to unavoidable micro-injuries occurring during removal from the plate, phenotypic and size variations of sham treated seedlings are small.
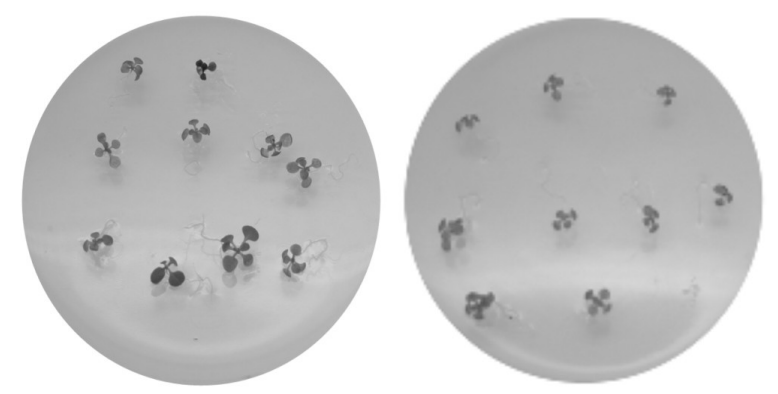

Figure 3. Representative images of plates with $A$. thaliana seedlings on MSagar, 7 days after performing the experimental procedure for nsPEF treatment, without applying electric field pulses (Sham control).

Figure 4 qualitatively demonstrates the effect of nanosecond pulsed electric field treatment on the plant growth 7 days after the treatment. The seedlings shown were treated with different electrical parameters, indicated for each plate.

At low field strength, $E=5 \mathrm{kV} / \mathrm{cm}$, Figure 4, upper row, the majority of plants exhibit natural growth and habitus for a pulse duration of $10 \mathrm{~ns}$ and $100 \mathrm{~ns}$, respectively. The plants obviously are larger than the sham-treated samples. This is a clear indication for positive growth stimulation due to pulsed electric field treatment.

The application of higher electric field strengths, $10 \mathrm{kV} / \mathrm{cm}$ and $20 \mathrm{kV} / \mathrm{cm}$, at a pulse duration of $25 \mathrm{~ns}$, Figure 4, middle row, leads to a plant size, which is comparable to that of the sham-treated seedlings.

A treatment with an electric field strength of $50 \mathrm{kV} / \mathrm{cm}$ inhibits any growth, in case the pulses are $100 \mathrm{~ns}$ long. In contrast, the application of the same amount of energy $\mathrm{W}=10000 \mathrm{~J} / \mathrm{kg}$ at $50 \mathrm{kV} / \mathrm{cm}$ has no lethal effect on the seedlings, when the pulses are $10 \mathrm{~ns}$ long. The plant size again is comparable to that of the sham-treated samples. Some 
phenotypic changes in leaf growth symmetry are visible, but the plants survived and grew. In all cases, the relative variation of the plant size of nsPEF-treated seedlings within a batch of 10 plants is larger than within the sham-treated samples. This might be dedicated to mutual shielding effects within the electroporation cuvettes.
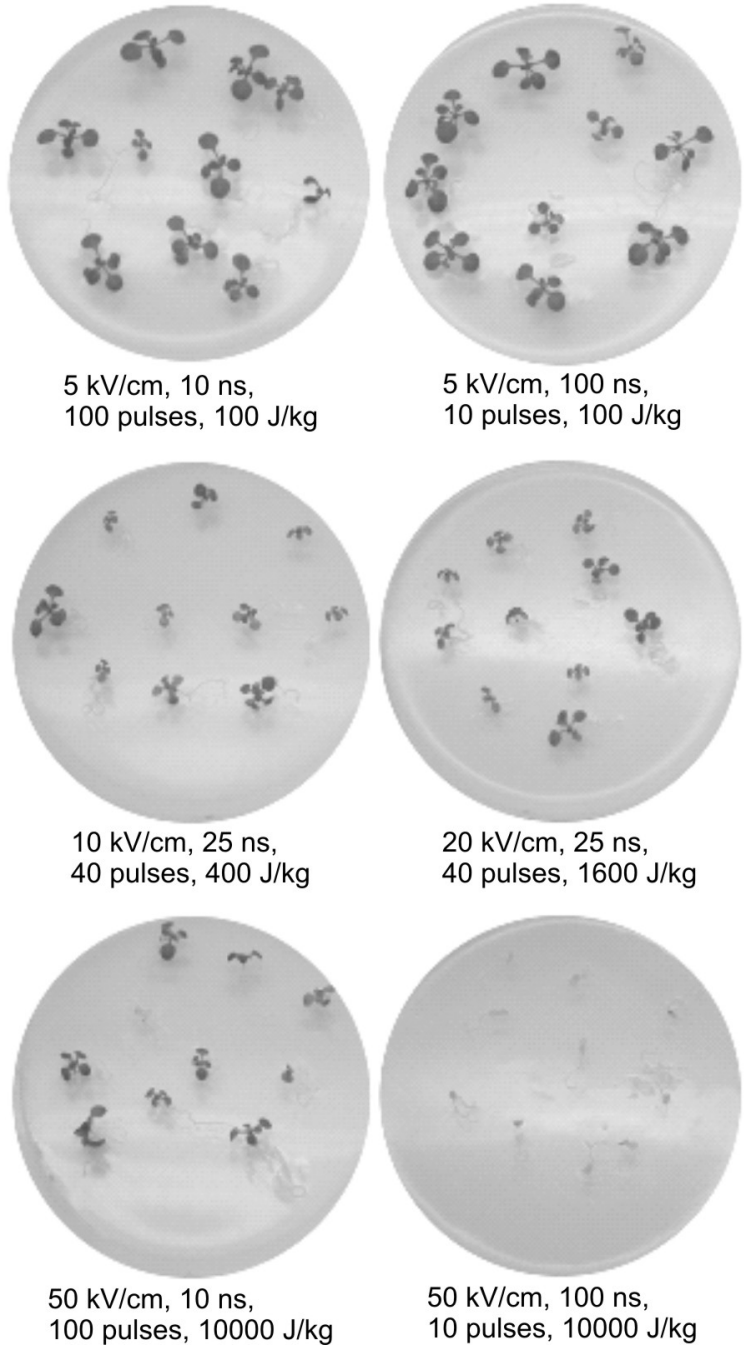

Figure 4. Representative images of plates with $A$. thaliana seedlings on MSagar, 7 days after treatment with different pulse parameters.

A more quantitative insight into the results is given in Figure 5, showing the total leaf area of 10 seedlings treated with 100 ns pulses 5 and 7 days after treatment, respectively.

All plants treated with $100 \mathrm{~ns}$ pulses at $50 \mathrm{kV} / \mathrm{cm}$, $\mathrm{W}=10000 \mathrm{~J} / \mathrm{kg}$ died, indicated by zero leaf area, Figure 5 . In all cases, except the $10000 \mathrm{~J} / \mathrm{kg}$ sample, the relative increase of leaf area from day 5 to day 7 is comparable, indicating no significant growth dynamics differences between sham-treated and nsPEFtreated samples. The leaf area of samples treated at $400 \mathrm{~J} / \mathrm{kg}$ and $1600 \mathrm{~J} / \mathrm{kg}$ is smaller than that of the sham treated seedlings. At the lowest applied treatment energy, $100 \mathrm{~J} / \mathrm{kg}$, an increase of more than $200 \%$ could be obtained 5 and 7 days after pulsed electric field treatment. The results propose a superposition of a growth stimulating and a growth inhibiting effect of pulsed electric field exposition on $A$. thaliana seedlings.

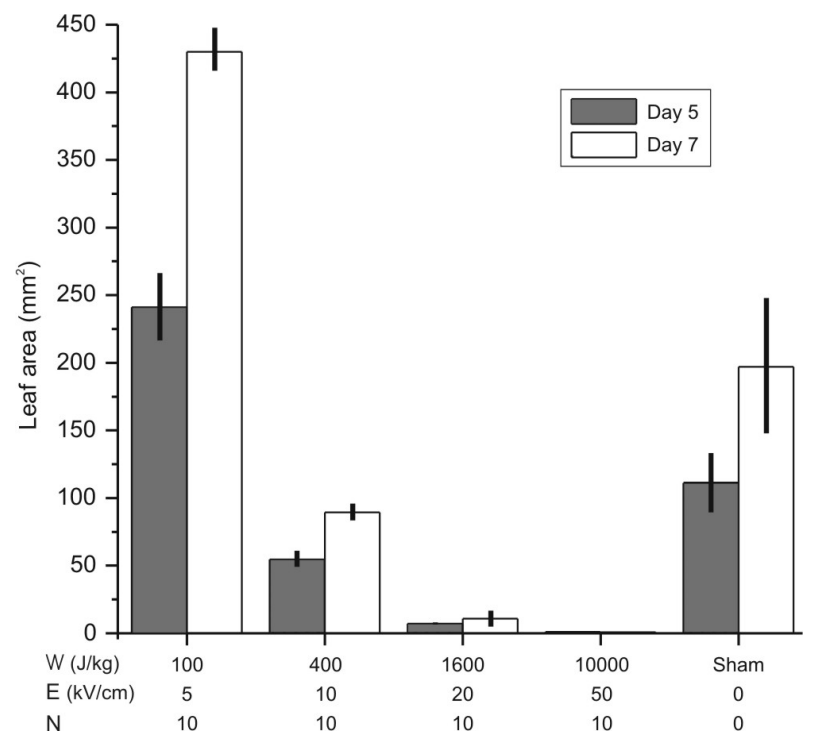

Figure 5. Averarge leaf area $\pm \mathrm{SE}$ of 10 seedlings of $A$. thaliana five and seven days after treatment with ten $100 \mathrm{~ns}$ pulses of different electric field amplitude values. $\mathrm{W}$ is the applied specific energy, E the electric field strength and $\mathrm{N}$ is the number of pulses.

It is reasonable, that the growth inhibiting effect is caused by electroporation of the plasmamembrane. In case of applying $100 \mathrm{~ns}$ pulses the impact on plant growth exhibits a clear dose dependency, typical for plasmamembrane permeabilization [29]. The higher the treatment energy the lower is the grown leaf area, Figure 5. At high specific treatment energies, electroporation unrepairably damages the seedling tissue, since the pulse duration is long enough for membrane charging and subsequent pore formation. Membrane charging followed by an onset of pore formation experimentally could be determined at comparable external field strengths on Jurkat cells to occur $5 \mathrm{~ns}$ after the beginning of the electric field pulse [30]. The remaining time obviously is sufficient for enhanced pore formation. In consequence, cells lose their cytoplasm and die off. It is supposed, that the degree of unrepairable tissue damage during PEF treatment can be detected by the leaf area development during subsequent plant growth.

This tendency continues for a pulse duration of $\mathrm{T}=25 \mathrm{~ns}$, Figure 6. Again all seedlings died at a specific treatment energy of $\mathrm{W}=10000 \mathrm{~J} / \mathrm{kg}$, whereas the developed leaf area at $400 \mathrm{~J} / \mathrm{kg}$ and $1600 \mathrm{~J} / \mathrm{kg}$ is larger compared to the $100 \mathrm{~ns}$ pulse treatment results. Provided that cell damage is caused by electroporation, the cell damage by enhanced formation of large pores at a $25 \mathrm{~ns}$ pulse exposure is lower, since the remaining time for pore formation after membrane charging is shorter. At $\mathrm{W}=100 \mathrm{~J} / \mathrm{kg}$ again the highest value of leaf area could be detected. For $25 \mathrm{~ns}$ pulses growth inhibition by plasmamembrane permeabilization becomes effective at higher treatment energies. Up to $\mathrm{W}=1600 \mathrm{~J} / \mathrm{kg}$ growth stimulation prevails.

When applying $10 \mathrm{~ns}$ pulses, plant growth can be obtained at all treatment energies, Figure 6. In all cases the grown leaf area is comparable to the sham treated sample or larger. For this pulse duration the time for the formation of aqueous pores 
large enough to cause cell death is too short. A potential formation of a large amount of nanopores, like proposed for mammalian cells when exposing them to pulses with a duration of several $10 \mathrm{~ns}[31,32]$ has no lethal effect on $A$. thaliana seedlings or effectively can be overcome during further plant growth. At the chosen treatment parameter range the growth stimulating effect is predominant.

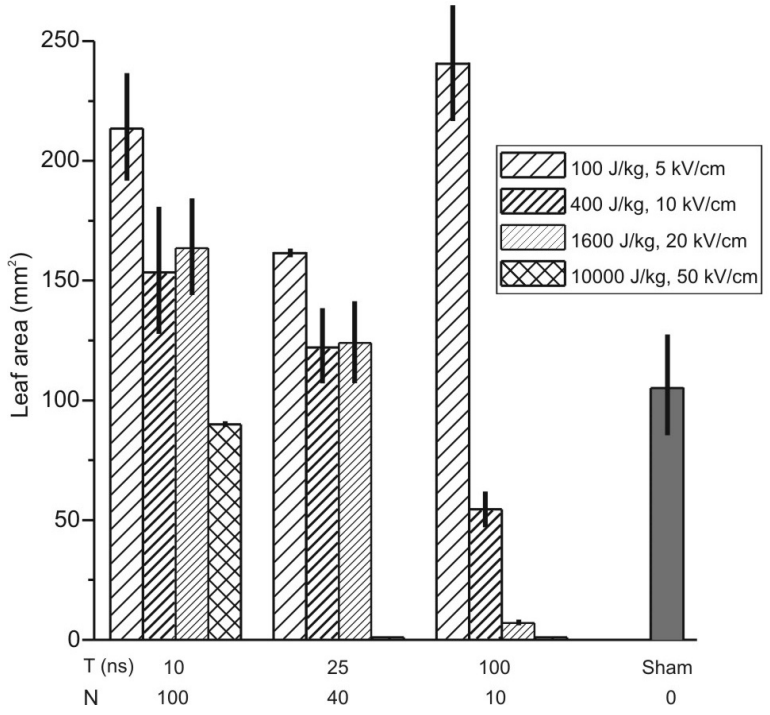

Figure 6. Average leaf area $\pm \mathrm{SE}$ of 10 seedlings of $A$. thaliana five days after treatment with different energies as a function of pulse duration $\mathrm{t}(\mathrm{ns}) . \mathrm{N}$ is the number of pulses.

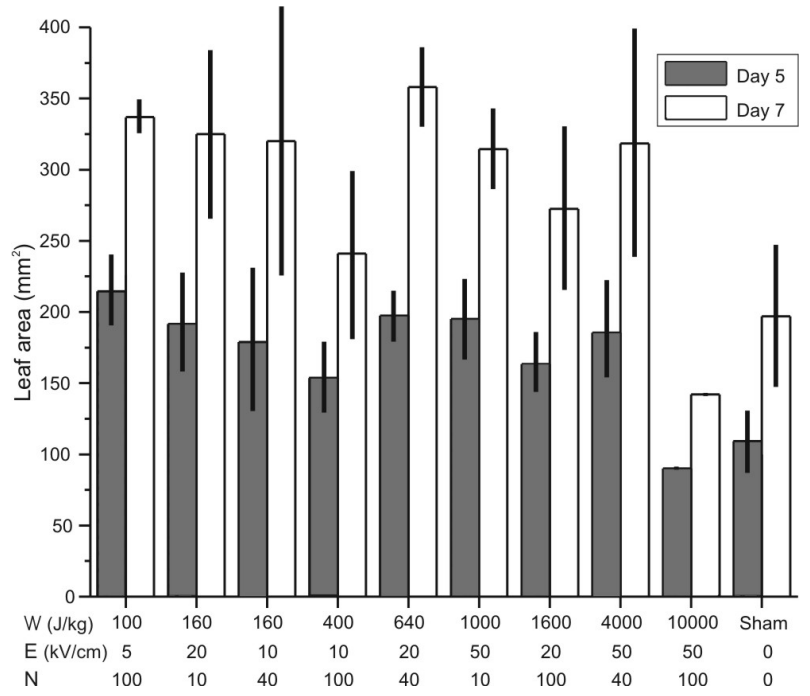

Figure 7. Average leaf area $\pm \mathrm{SE}$ of 10 seedlings of $A$. thaliana five and seven days after treatment with different pulse parameters. Pulse duration was $10 \mathrm{~ns}$, except for the sham-control. $\mathrm{W}$ is the applied specific energy, E the electric field strength, $\mathrm{N}$ is the number of pulses.

Figure 7 shows the growth stimulating effect of $10 \mathrm{~ns}$ pulses at a higher treatment energy resolution. No distinct energy dependency compareable to membrane permeabilization at $100 \mathrm{~ns}$ pulses could be obtained. A growth stimulating effect of a $10 \mathrm{~ns}$ pulse exposition could be obtained for specific treatment energies up to $4000 \mathrm{~J} / \mathrm{kg}$.

A feasible explanation for growth stimulation resulting from nsPEF exposure could be stress response mechanisms of plants. Stress responses of plant cells are manifold. Galindo et al observed a decrease in cell wall permeability of potato cells resulting from PEF treatment. They found evidence, that production of $\mathrm{H}_{2} \mathrm{O}_{2}$ by cell wall associated peroxidases may be involved in that response [42]. $\mathrm{H}_{2} \mathrm{O}_{2}$ is known to play a role in plant responses, involved in wound healing [43]. Lennartsson comprehensively reported about increased growth of plants in response to stress factors [33]. Belsky et al [34] described a positive growth stimulation yielding a fast growth in response to damages by herbivores. Rapid growth may have evolved as a mechanism to reduce the negative impacts of all types of damage to the plant tissue, sometimes resulting in increased growth rates and higher total biomass production. In plants, various external stimuli, including mechanical signals, ozone, salinity and temperature lead to a rapid increase in the cytosolic calcium level $[35,36,40]$, followed by adequate changes in the physiology, growth and development of the organisms. Many observations strongly indicate, that the cytosolic calcium level plays a central role in the control of the mechanisms of sensing, amplification, decoding and quenching of the stimulus. For undisturbed conditions, the free calcium concentration in the cytosol is very low, usually in the range of 100 and $200 \mathrm{nM}$ [37], 10000 times lower than that in intracellular compartments like the vacuole or the endoplasmatic reticulum.

The application of nanosecond pulsed electric fields to mamalian cells has been reported to result in fast, transient rises in free intracellular calcium [38, 14]. In Jurkat cells, Scarlett et al [15] observed a fast, field dependent release of calcium only from intracellular stores, mainly the endoplasmatic reticulum for $60 \mathrm{~ns}$ pulses at $25 \mathrm{kV} / \mathrm{cm}$ and $50 \mathrm{kV} / \mathrm{cm}$, most probable by charging and affecting intracellular membranes. At higher field strength, $100 \mathrm{kV} / \mathrm{cm}$, the increase in free cytosolic calcium was due to internal calcium release and to an influx of calcium across the cell membrane indicating the onset of an impact of plasmamembrane electroporation [39]. It is reasonable, that a nsPEF exposition on plant cells causes similar effects.

High electric field pulses with a rise time on the order of $1.5 \mathrm{~ns}$ cause a large voltage drop across intracellular membranes during the first nanoseconds [13]. This initial voltage drop is independent of the pulse duration in case pulses of different duration exhibit the same rise time. Following, a growth stimulating effect based on inner membrane charging is feasible for $100 \mathrm{~ns}$ pulses, too, if the stimulating effect is not masked by a counterproductive influence of electroporation at a later time during field exposition. This would explain the observed leaf area increase at $5 \mathrm{kV} / \mathrm{cm}$ and $100 \mathrm{~ns}$ pulse duration.

We hypothesize, that the growth stimulating effect of nsPEF exposure observed in our experiments is due to a field induced change in the concentration of free cytosolic calcium from intracellular calcium stores, which triggers stress compensating and growth stimulating mechanisms 
in the seedlings. The stress response may lead to the observed increase in leaf area. The stimulating effect is masked by necrosis caused by irreversible electroporation of the plasmamembrane. For longer pulses, necrosis already dominates at comparable low treatment energy and electric field strength values. In this case a growth stimulation can only be observed at the lowest investigated field strength resulting in reversible plasmamembrane permeabilization which most probable can be compensated or repaired during subsequent plant growth.

\section{SUMMARY AND CONCLUSION}

Seven days old seedlings of $A$. thaliana were exposed to nsPEFs with a duration of $10 \mathrm{~ns}, 25 \mathrm{~ns}$ and $100 \mathrm{~ns}$. Ensuing plant growth was assessed by determination of the grown leaf area 5 and 7 days after nsPEF treatment. At a field strength of $5 \mathrm{kV} / \mathrm{cm}$ and a specific treatment energy of $100 \mathrm{~J} / \mathrm{kg}$ a growth stimulating effect could be revealed for all pulse durations. At higher treatment energies and predominantly for long pulses, the growth stimulating effect is masked by necrosis, caused by plasmamembrane electroporation. It is assumed, that growth stimulation is a stress response of the organism against nsPEF exposure. This response might be triggered by a calcium release from internal stores, like it is evident for nsPEF-treated mammalian cells. Future work will focus on calcium imaging of nsPEF-treated plant cells.

\section{ACKNOWLEDGEMENTS}

We would like to thank Sonja Becker and Janine Straeter for their valuable assistance in the plant cultivation and treatment procedures and Ruediger Wuestner for competent ns-pulse generator preparation and operation and for diligent execution of nsPEF treatment experiments.

\section{REFERENCES}

[1] E. Neumann and K. Rosenheck, "Permeability changes induced by electric pulses in vesicular membranes", J. Membrane Biology, Vol. 10, pp. 279-290, 1972.

[2] U. Zimmermann, G. Pilwat and F. Riemann, "Dielectric breakdown of cell membranes“, Biophysical J., Vol. 14, pp. 881-899, 1974.

[3] J. C. Weaver and Y. U. Chizmadzhev, "Theory of electroporation: A review", Bioelectrochemistry and Bioenergetics, Vol. 41, pp. 135$160,1996$.

[4] M. P. Rols and J. Teissié, "Electropermeabilization of mammalian cells to macromolecules: Control by pulse duration", Biophysical J., Vol. 75, pp. 1415-1432, 1998.

[5] L. M. Mir, L. F. Glass, G. Sersa, J. Teissie, C. Domenge, D. Miklavcic, M. J. Jaroszeski, S. Orlowaska, D. S. Reintgen, Z. Rudolfs, M. Belehradek, R. Gilbert, M.-P. Rols, J. Belehradek jr., J. M. Bachaud, R. Deconti, B. Stabuc, M. Cemazar, P. Coninx and R. Heller, "Effective treatment of cutaneous and subcutaneous malignant tumors by electrochemotherapy", British J. Cancer, Vol. 77, pp. 23362342, 1998.

[6] A. H. J. Sale and W. A. Hamilton, "Effects of high electric fields on microorganisms 1. Killing of bacteria and yeasts", Biochimica et Biophysica Acta, Vol. 148, pp. 781-788, 1967.
[7] C. Gusbeth, W. Frey, H. Volkmann, T. Schwartz and H. Bluhm, "Pulsed electric field treatment for bacteria reduction and its impact on hospital wastewater", Chemosphere, Vol. 75, pp. 228-233, 2009.

[8] G. V. Barbosa-Canovas, M. M. Gongora-Nieto, U. R. Pothakamury and B. G. Swanson, Preservation of Foods with Pulsed Electric Fields, Academic Press, Inc., New York, 1999.

[9] M. Sack and H. Bluhm, "New measurement methods for an industrialscale electroporation facility for sugar beets", IEEE Trans. Industry Applications, Vol. 44, pp. 1074-1083.

[10] A. Angersbach, V. Heinz and D. Knorr, "Effects of pulsed electric fields on cell membranes in real food systems", Innovative Food Science and Emerging Technologies, Vol. 1, No. 2, pp. 135-149, 2000.

[11] K. H. Schoenbach, S. J. Beebe and E. S. Buescher, "Intracellular effect of ultrashort electrical pulses", Bioelectromagnetics, Vol. 22, pp. 440-448, 2001.

[12] T. R. Gowrishankar, A. T. Esser, Z. V. Vasilkoski, K. C. Smith and J. C. Weaver, "Microdosimetry for conventional and supraelectroporation in cells with organelles", Biochemical and Biophysical Research Communications, Vol. 341, pp. 1266-1276, 2006.

[13] K. H. Schoenbach, R. J. Joshi, J. F. Kolb, N. Chen, M. Stacey, P. F. Blackmore, E. S. Buescher and S. J. Beebe, "Ultrashort electrical pulses open a new gateway into biological cells", Proc. IEEE, Vol. 92, pp. 1122-1137, 2004.

[14] P. T. Vernier, Y. Sun, L. Marcu, S. Salemi, C. M. Craft and M. A. Gundersen, "Calcium bursts induced by nanosecond electric pulses", Biochemical and Biophysical Research Communications, Vol. 310, pp. 286-295, 2003.

[15] S. S. Scarlett, J. A. White, P. F. Blackmore, K. H. Schoenbach and J. F. Kolb, "Regulation of intracellular calcium concentration by nanosecond pulsed electric fields", Biochimica et Biophysica Acta, doi:10.1016/j.bbamem.2009.02.006, 2009.

[16] P. T. Vernier, M. J. Ziegler, Y. Sun, W. V. Chang, M. A. Gundersen and D. P. Tieleman, "Nanopore formation and phosphatidylserine externalization in a phospholipid bilayer at high transmembrane potential“", J. Amer. Chem. Soc., Vol. 128, pp. 6288-6289, 2006.

[17] M. Stacey, J. Stickley, P. Fox, V. Statler, K. H. Schoenbach, S. J. Beebe and E. S. Buescher, "Differential effects in cells exposed to ultra-short, high intensity electric fields: cell survival, DNA damage, and cell cycle analysis", Mutation Research, Vol. 542, pp. 65-75, 2003.

[18] R. Nuccitelli, U. Pliquett, X. Chen, W. Ford, R. J. Swanson, S. J. Beebe, J. F. Kolb and K. H. Schoenbach, "Nanosecond pulsed electric fields cause melanomas to self-destruct", Biochemical and Biophysical Research Communications, Vol. 343, pp. 351-360, 2006.

[19] S. Tsukamoto, T. Maeda, M. Ikeda and H. Akiyama, "Application of pulsed power to mushroom culturing", $14^{\text {th }}$ IEEE Intern. Pulsed Power Conf., Vol. 2, pp. 1116-1119, 2003.

[20] K. Takaki, K. Kanesawa, N. Yamazaki, S. Mukaigawa, T. Fujiwara, K. Takahasi, K. Yamasita and K. Nagane, "Application of IES pulsed power generator for mushroom cultivation", $16^{\text {th }}$ IEEE Intern. Pulsed Power Conf., Vol. 2, pp. 1253-1256, 2007.

[21] E. Costanzo, "The influence of an electric field on the growth of soy seedlings", J. Electrostatics, Vol. 66, pp. 417-420, 2008.

[22] D. Sleper, M. S. Pathan, B. Camps-Raga, S. Tantong, P. Kirawanich, J. E. Thompson and N. E. Islam, "Optimization of soybeans as a biofuel resource through germination studies under electromagnetic fields", Proc. $18^{\text {th }}$ Intern. Symposium on EMC, Munich, Germany, pp. 297-300, 2007.

[23] J. D. Moon and H. S. Chung, "Acceleration of germination of tomato seed by applying AC electric and magnetic fields", J. Electrostatics, Vol. 48, pp. 103-114, 2000.

[24] R. Cramariuc, V. Donescu, M. Popa and B. Cramariuc, "The biological effect of the electrical field treatment on the potato seed: Agronomic evaluation", J. Electrostatics, Vol. 63, pp. 837-846, 2005.

[25] C. H. Bachman and M. Reichmanis, "Some effects of high electrical fields on barley growth", Intern. J. Biometeorology, Vol. 17, pp. 253$262,1973$.

[26] G.P. Rédei, "Supervital mutants of Arabidopsis", Genetics, Vol. 47, pp. 443-460, 1962. 
[27] T. Murashige and F. Skoog, "A revised medium for rapid growth and bio-assays with tobacco tissue cultures", Physiol. Plant, Vol. 15, pp. 473-497, 1962.

[28] W.S. Rasband, "ImageJ", U. S. National Institutes of Health, Bethesda,

Maryland, USA, http://rsb.info.nih.gov/ij/, 1997-2008.

[29] B. L. Ibey, S. Xiao, K. H. Schoenbach, M. R. Murphy and A. G. Pakhomov, "Plasma membrane permeabilization by $60-$ and $600-\mathrm{ns}$ electric pulses is determined by the absorbed dose", Bioelectromagnetics, Vol. 30, pp. 92-99, 2009.

[30] W. Frey, J. A. White, R. O. Price, P. F. Blackmore, R. P. Joshi, R. Nuccitelli, S. J. Beebe, K. H. Schoenbach and J. F. Kolb, "Plasma Membrane Voltage Changes during Nanosecond Pulsed Electric Field Exposure", Biophysical J., Vol. 90, pp. 3608-3615, 2006.

[31] T. R. Gowrishankar and J. C. Weaver, "Electrical behaviour and pore accumulation in a multicellular model for conventional and supraelectroporation", Biochemical and Biophysical Research Communications, Vol. 349, pp. 643-653, 2006.

[32] Q. Hu, R. P. Joshi and K. H. Schoenbach, "Simulations of nanopore formation and phosphatidylserine externalization in lipid membranes subjected to a high-intensity, ultrashort electric pulse “, Phys. Rev. E: Stat. Nonlin. Soft Matter Physics, Vol. 72, No. 3, pp. 031902.1$031902.10,2005$.

[33] T. Lennartsson, P. Nilsson and J. Tuomi, "Induction of overcompensation in the field gentian, Gentianella campestris", Ecology, Vol. 79, pp. 1061-1072, 1998.

[34] A. J. Belsky, W. P. Carson, C. L. Jensen and G. A. Fox, "Overcompensation by plants: Herbivore optimization or red herring ?, Evolutionary Ecology, Vol. 7, pp. 109-121, 1993.

[35] D. Lecourieux, C. Mazars, N. Pauly, R. Ranjeva and A. Pugin, "Analysis and effects of cytosolic free calcium increases in response to elicitors in Nicotiana plumbaginifolia cells", Plant Cell, Vol. 14, pp. 2627-2641, 2002.

[36] D. Sanders, C. Brownlee and J. F. Harper, "Communicating with calcium", Plant Cell, Vol. 11, pp. 691-706, 1999.

[37] D. S. Bush, "Calcium regulation in plant cells and its role in signaling", Annu. Rev. Plant Physiol. Plant Mol. Biol., Vol. 46, pp. 95-122, 1995.

[38] E. S. Buescher, R. R. Smith and K. H. Schoenbach, "Submicrosecond intense pulsed electric field effects on intracellular free calcium: mechanisms and effects“, IEEE Trans. Plasma Sci., Vol. 32, pp. 1563$1571,2004$.

[39] J. A. White, P. F. Blackmore, K. H. Schoenbach and S. J. Beebe., "Stimulation of capacitative calcium entry in HL-60 cells by nanosecond pulsed electric fields", J. Biological Chemistry, Vol. 279, pp. 22964-22972, 2004.

[40] R. A. Bressan and P. M. Hasegawa, "Plants use calcium to resolve salt stress", Trends in plant science, Vol. 3, pp. 411-412, 1998.

[41] W. Frey, M. Sack, R. Wuestner and G. Mueller, "Gas-Insulated SelfBreakdown Spark Gaps: Aspects on Low-Scattering and LongLifetime Switching", Acta Physica Polonica A, Vol. 115, pp. 1016$1018,2009$.

[42] F. G. Galindo, P. T. Vernier, P. Dejmek, A. Vicente and M. A. Gunderson,"Pulsed Electric Field Reduces the Permeability of Potato Cell Wall“, Bioelectromagnetics, Vol. 29, pp. 296-301, 2008.

[43] F. A. Razem and M. A. Bernards, "Reactive oxygen species production in association with suberization: Evidence for a NADPHdependent oxidase", J. Experimental Botany, Vol. 54, No. 384, pp. 935-941, 2003.

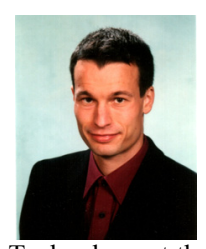

Christian Eing was born in Karlsruhe, Germany, in 1973. $\mathrm{He}$ received his Diploma and the Ph.D. degrees in biology from the University of Karlsruhe, Germany, in 2001 and 2006, respectively. During this time, he worked in the research fields of electrophysiology, yeast genetics and plant biochemistry. In 2006 he joined the Bioelectrics Group at the Institute for Pulsed Power and Microwave Technology at the Research Center Karlsruhe, KIT, Germany. Currently, he is working in the field of membrane biology and electroporation, focussing on basic research and industrial applications.

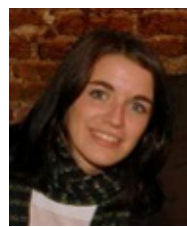

Simone Bonnet was born in Bretten, Germany, in 1983. She performed her diploma thesis on homologous recombination in plants (2008-2009) in the group of Holger Puchta, Botanical Institute of the University of Karlsruhe, KIT, Germany.

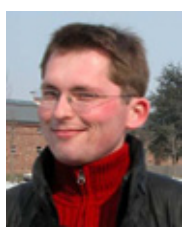

Michael Pacher was born in Karlsruhe, Germany in 1977. He received the diploma degree in biology in 2004 and the $\mathrm{Ph} . \mathrm{D}$. degree from the University of Karlsruhe, Germany in 2008. Since 2008 he is a postdoctoral fellow with Holger Puchta at the Botanical Institute, University of Karlsruhe, KIT, Germany.

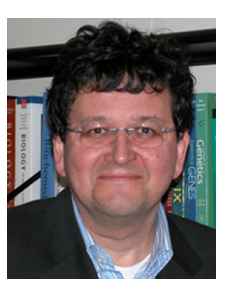

Holger Puchta was born in Ingolstadt, Germany, in 1960. He received the diploma degree in biochemistry from the University of Tübingen, Germany, in 1988, performed his Ph.D. study at the Max-Planck-Institute for Biochemistry in Munich, Germany, and worked as research fellow at the Friedrich-Miescher Institute in Basel, Switzerland from 1989 to 1995. From 1995 to 2002 he was group leader at the Institute of Plant Genetics and Crop Plant Research (IPK) in Gatersleben, Germany. In 2000 he obtained his habilitation in genetics from the university of Halle, Germany. Since 2002 he is full professor at the Botanical Institute of the University of Karlsruhe, KIT.

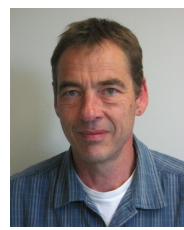

Wolfgang Frey was born in Schwaebisch Gmuend, Germany in 1960. He received his diploma degree in high voltage technology from the University of Karlsruhe in 1989. Subsequently he was an assistant professor at the High Voltage Institute of the University of Karlsruhe, working on new pulse forming concepts, high voltage test engineering and gas insulated spark gaps. In 1996 he received the Ph.D. degree on laser triggering of rail gap switches from the University of Karlsruhe. In 1997 he joined the pulsed power group of the former Research Center of Karlsruhe, now Campus North of KIT. He started with surface coating by pulsed electron beam ablation, worked on electrodynamic fragmentation for material processing and switched to pulsed electric field effects on biological matter in 2001. He worked on pulsed electric field treatment for bacterial decontamination and cell ingredient extraction. Since 2006 he is a team leader in bioelectrics at the Institute for Pulsed Power and Microwave Technology, KIT, Campus North. 